\title{
Discovery of Pyrido[3', $\left.2^{\prime}: 5,6\right]$ thiopyrano[4,3- $\left.d\right]$ pyrimidine-Based Antiproliferative Multikinase Inhibitors
}

\author{
Silvia Salerno, ${ }^{\dagger}$ Elisabetta Barresi, ${ }^{\dagger}$ Aída Nelly García-Argáez, ${ }^{\ddagger}$ Sabrina Taliani, ${ }^{*}{ }^{\dagger}$ (0 Francesca Simorini, ${ }^{\dagger}$ \\ Giorgio Amendola, ${ }^{\S \odot}$ Stefano Tomassi, ${ }^{\S}$ Sandro Cosconati, ${ }^{*}{ }^{\S} \odot$ Ettore Novellino, ${ }^{\prime \odot}$ \\ Federico Da Settimo, ${ }^{\dagger}$ Anna Maria Marini, ${ }^{\dagger}$ and Lisa Dalla Via ${ }^{*}$ \\ ${ }^{\dagger}$ Dipartimento di Farmacia, Università di Pisa, Via Bonanno 6, 56126 Pisa, Italy \\ ${ }^{\ddagger}$ Dipartimento di Scienze del Farmaco, Università di Padova, Via Marzolo 5, 35131 Padova, Italy \\ ${ }^{\S}$ DiSTABiF, Università della Campania Luigi Vanvitelli, Via Vivaldi 43, 81100 Caserta, Italy \\ "Dipartimento di Farmacia, Università di Napoli “Federico II”, Via D. Montesano 49, 80131 Napoli, Italy
}

Supporting Information

\begin{abstract}
Protein kinases dysregulation is extremely common in cancer cells, and the development of new agents able to simultaneously target multiple kinase pathways involved in angiogenesis and tumor growth may offer several advantages in the treatment of cancer. Herein we report the discovery of new pyridothiopyranopyrimidine derivatives (2-4) showing high potencies in VEGFR-2 KDR inhibition as well as antiproliferative effect on a panel of human tumor cell lines. Investigation on the selectivity profile of the representative 2 -anilino-substituted compounds $3 \mathbf{b}, 3 \mathbf{i}$, and $3 \mathbf{j}$ revealed a multiplicity of kinase targets that should account for the potent antiproliferative effect produced by these pyridothiopyranopyrimidine derivatives.
\end{abstract}

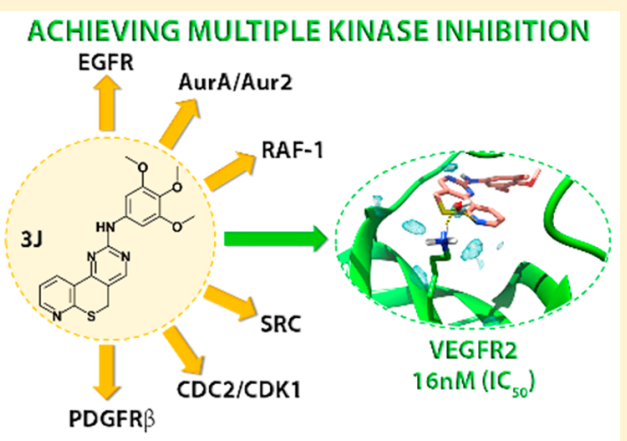

KEYWORDS: Pyridothiopyranopyrimidines, multitargeted kinase inhibitors, KDR kinase, antiproliferative activity

$\mathrm{P}$ rotein kinases dysregulation is extremely common in cancer cells; thus, they have become attractive targets for the development of anticancer drugs, including small molecule tyrosine kinase inhibitors (TKIs) and monoclonal antibodies. ${ }^{1}$ In solid malignancies, it is unusual for a single kinase abnormality to be the sole cause of the disease; more likely, multiple signaling pathways are dysregulated, and unless it is possible to target a single key underlying defect, it is likely that therapies will be more effective by inhibiting a number of downstream targets. ${ }^{1}$ Indeed, although selective TKIs are available with some clinical successes (i.e., imatinib, cediranib, vatalanib, erlotinib, gefitinib), it has become evident that solid tumors can activate several pathways of recovery and resistance that allow them to bypass the inhibition of a single biochemical process. $^{1}$

Thus, therapeutic protocols are designed to target multiple kinase pathways. This can be achieved by using a combination of several highly selective agents for a single target or by employing a single molecule able to inhibit multiple kinases, a multitargeted kinase inhibitor (MTKI). ${ }^{1}$ To date, a number of TKIs with reported activity against one or multiple kinases have successfully cleared the clinical path and have been approved for clinical use. Benefits in developing MTKIs include the reduction of resistance insurgence, wide spectra of application, and effectiveness as combinatorial therapy without the disadvantages of using multiple selective agents. ${ }^{2,3}$ Examples of MTKIs agents currently licensed for use include sorafenib, ${ }^{4}$ sunitinib, ${ }^{5}$ lapatinib, ${ }^{6}$ pazopanib, ${ }^{7}$ vandetanib, ${ }^{8}$ and regorafenib. ${ }^{9}$

Many of the aforementioned MTKIs are antiangiogenic TKIs. In normal physiological conditions, angiogenesis is well controlled by pro- and antiangiogenic factors, and it is only promoted during particular circumstances, such as wound healing and repair. ${ }^{10}$ Conversely, in cancer, this balance is disturbed, resulting in the so-called "angiogenic switch". ${ }^{10}$ The vascular endothelial growth factor (VEGF) pathway represents one of the most important positive modulators of angiogenesis and, within the VEGF family members (VEGF-A, VEGF-B, VEGF-C, VEGF-D, VEGF-E), VEGF-A (commonly referred to as VEGF) is the major mediator of tumor angiogenesis and signals through VEGFR-2, the main VEGF signaling receptor. ${ }^{11}$ The binding of the VEGF ligand to its cognate receptor initiates the activation of downstream signaling pathways, including the RAF-mitogen activated protein kinase (MEK), extracellular regulated kinase (ERK), and phosphoinositide 3-kinase (PI3K) pathways, which ultimately lead to endothelial cell activation, proliferation, migration, and survival. ${ }^{12,13}$

Special Issue: Highlighting Medicinal Chemistry in Italy

Received: October 24, 2018

Accepted: January 17, 2019

Published: January 17, 2019 
For several decades the research efforts of our group have been aimed at developing polyheterocyclic-based derivatives as new antiproliferative agents. ${ }^{14-19}$ In particular, some studies on the benzothiopyranopyrimidine system gave rise to the disclosure of novel compounds endowed with interesting antiangiogenic properties, in which the core scaffold was decorated with a pendant aryl moiety (phenyl, phenylamino, benzylamino) at the 2-position (general formula 1, Chart 1). ${ }^{18,19}$

Chart 1. General Structures of Previously Reported Benzothiopyranopyrimidines $(1)^{18,19}$ and Newly Synthesized Pyridothiopyranopyrimidines (2-4)
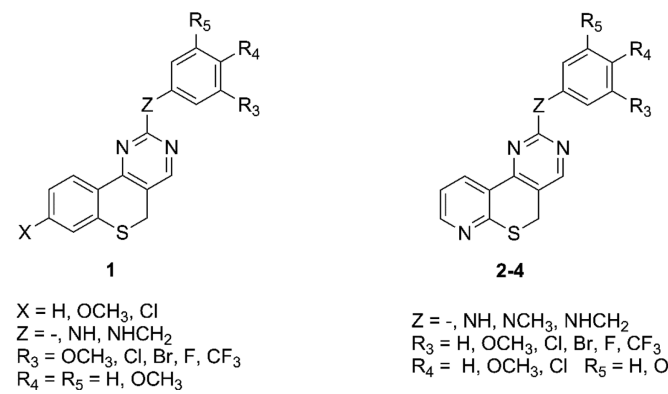

$\mathrm{Z}=-, \mathrm{NH}, \mathrm{NCH}_{3}, \mathrm{NHCH}_{2}$ $\mathrm{R}_{3}=\mathrm{H}, \mathrm{OCH}_{3}, \mathrm{Cl}, \mathrm{Br}, \mathrm{F}, \mathrm{CF}_{3}$ $\mathrm{R}_{4}=\mathrm{H}, \mathrm{OCH}_{3}, \mathrm{Cl} \mathrm{R} \mathrm{R}_{5}=\mathrm{H}, \mathrm{OCH}_{3}$

The majority of these compounds featuring a 2-aniline moiety displayed a pronounced inhibitory profile (low micromolar/ submicromolar $\mathrm{IC}_{50}$ values) on human kinase insert domain receptor (KDR) and promising antiproliferative activity on human umbilical vein endothelial cells (HUVEC), as well as on a panel of three human tumor cell lines (A-431, epidermoid carcinoma; HeLa, cervix adenocarcinoma; and MSTO-211H, biphasic mesothelioma).

The crucial role of the 2-anilino side moiety in the interaction with the KDR domain of VEGFR-2 was substantiated by molecular docking calculations. ${ }^{19}$ The model showed that the interaction of the inhibitor with the enzyme active site could be mediated by a double $\mathrm{H}$-bond that the nitrogen at 3-position of the benzothiopyranopyrimidine scaffold and the adjacent aniline $\mathrm{NH}$ at the 2-position establish with the backbone $\mathrm{NH}$ and $\mathrm{CO}$ of C919, in the enzyme hinge region, respectively. In addition, structure-activity relationships (SARs) supported the finding that this group is pointing outward of the binding pocket and engages a cation $-\pi$ interaction with the K838. ${ }^{19}$

According to these studies, the presence of the positively charged K868 within the same cleft suggests that modifications of the electronic properties of the benzothiopyranopyrimidine scaffold may represent an opportunity for further structural optimization of this promising system. Thus, starting from these results, in the present study we designed three series of pyridothiopyranopyrimidine derivatives (2-4, Chart 1 and Scheme 1), all conceived as azaisosters of the previously described benzothiopyranopyrimidines $1 .{ }^{18,19}$ The introduction into the chromophore of a nitrogen atom could, in principle, produce a beneficial effect on the interaction within the hydrophobic ATP cleft hosting the heterocyclic system. Indeed, this further nitrogen atom, besides modulating the electronic properties of the chromophore, could also provide an additional or alternative anchoring point for the interaction with the target enzyme.

Analogously to the benzothiopyranopyrimidines, all the products investigated featured an aryl moiety inserted at the 2position of the tricyclic system. With the aim of performing critical SAR studies, libraries of 2-phenyl- (2a-c, Scheme 1), 2phenylamino- (3a-k, Scheme 1$)$, and 2-benzylamino- $(\mathbf{4 a - h}$, Scheme 1) substituted analogs characterized by diverse substitution patterns on the side phenyl ring were synthesized and biologically evaluated.

The synthesis of compounds $\mathbf{2 a - c}$ and $\mathbf{4 a - h}$ was accomplished through the reaction between the 3-dimethylaminomethylene derivative $5^{20}$ and the commercial benzamidines $(6 \mathbf{a}-\mathbf{c})$ or the benzylguanidines $(7 \mathbf{a}-\mathbf{h}),{ }^{21}$ in an ethanolic refluxing solution, in the presence of sodium ethoxide (Scheme 1 ). Reaction of the 2 -aminopyrimidino derivative $8^{22}$ with the commercial phenyl iodides $9 \mathbf{a}-\mathbf{j}$, in anhydrous dioxane and in the presence of $\mathrm{K}_{2} \mathrm{CO}_{3}, N, N^{\prime}$-dimethylethylendiamine (DMEDA), and CuI, afforded compounds $\mathbf{3 a - j}$ (Scheme 1). For the synthesis of $\mathbf{3 k}, \mathbf{5}^{20}$ was reacted with methyl guanidine hydrochloride to furnish the $\mathrm{N}$-methyl-substituted derivative 10, which was subsequently $N$-arylated by treatment with phenyl iodide, under the same conditions specified above (Scheme 1). Compounds 2-4 were then tested for their ability to inhibit the KDR kinase activity by a fluorimetric assay on a recombinant human KDR, using semaxanib as a reference. ${ }^{23}$ Table 1 lists the

\section{Scheme $1^{a}$}

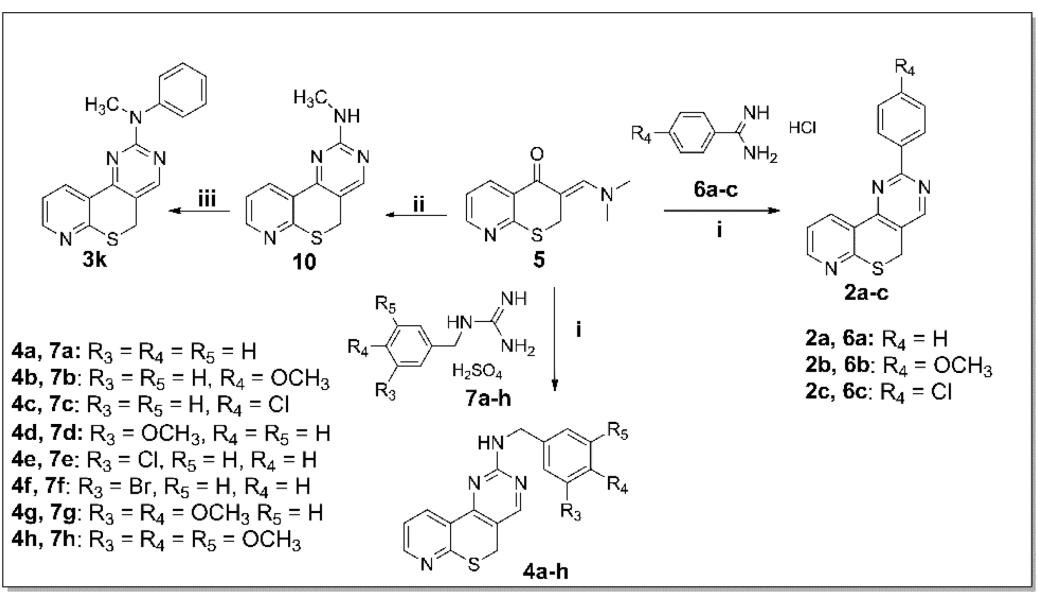

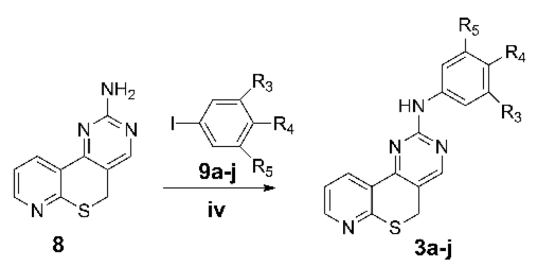

3a, 9a: $R_{3}=R_{4}=R_{5}=H$

3f, 9f: $R_{3}=B r, R_{5}=R_{4}=H$ 3b, 9b: $R_{3}=R_{5}=H, R_{4}=O C H_{3} 3 g, 9 g: R_{3}=F, R_{4}=R_{5}=H$ 3c, 9c: $R_{3}=R_{5}=H, R_{4}=\mathrm{Cl} \quad 3 h, 9 h: R_{3}=C_{3}, R_{5}=R_{4}=H$ 3d, 9d: $R_{3}=O C H_{3}, R_{4}=R_{5}=H \quad 3 i, 9 i: R_{3}=R_{4}=O C H_{3} R_{5}=H$ 3e, $9 \mathrm{e}: \mathrm{R}_{3}=\mathrm{Cl}, \mathrm{R}_{5}=\mathrm{R}_{4}=\mathrm{H} \quad 3 \mathrm{j}, 9 \mathrm{j}: \mathrm{R}_{3}=\mathrm{R}_{4}=\mathrm{R}_{5}=\mathrm{OCH}_{3}$

${ }^{a}$ Reagents and conditions: (i) EtONa, refluxing ethanol; (ii) methylguanidine hydrochloride, EtONa, refluxing ethanol; (iii) phenyl iodide, $\mathrm{K}_{2} \mathrm{CO}_{3}$, DMEDA, CuI, dioxane; (iv) $\mathrm{K}_{2} \mathrm{CO}_{3}$, DMEDA, CuI, dioxane. 
Table 1. KDR Enzyme Inhibitory Activity and Human Cell Growth Inhibition of Derivatives 1a-j, 2a-c, 3a-k, 4a-h, and Semaxanib as Reference

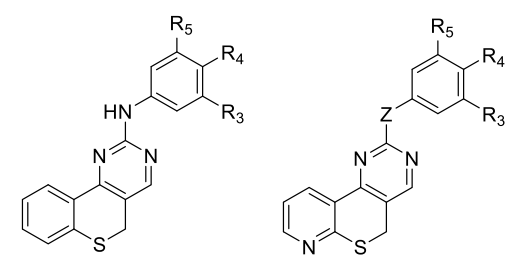

a-j

2 a-c, 3 a-k, 4 a-h

\begin{tabular}{|c|c|c|c|c|c|c|c|c|c|c|}
\hline \multirow[b]{2}{*}{ cpd } & \multirow[b]{2}{*}{$\mathrm{Z}$} & \multirow[b]{2}{*}{$\mathrm{R}_{3}$} & \multirow[b]{2}{*}{$\mathrm{R}_{4}$} & \multirow[b]{2}{*}{$\mathrm{R}_{5}$} & \multirow[b]{2}{*}{$\operatorname{KDR}(\%)^{a}$} & \multirow[b]{2}{*}{$\operatorname{KDR~IC}_{50}(\mu \mathrm{M})^{b}$} & \multicolumn{4}{|c|}{$\mathrm{GI}_{50}(\mu \mathrm{M})^{c}$} \\
\hline & & & & & & & HUVEC & HeLa & A-431 & MSTO-211H \\
\hline $1 \mathbf{a}^{d}$ & $\mathrm{NH}$ & $\mathrm{H}$ & $\mathrm{H}$ & $\mathrm{H}$ & 54 & 8.2 & 2.4 & $10.2 \pm 2.1$ & $>20$ & $11.7 \pm 1.3$ \\
\hline $1 \mathbf{b}^{d}$ & $\mathrm{NH}$ & $\mathrm{H}$ & $\mathrm{OCH}_{3}$ & $\mathrm{H}$ & 67 & 2.7 & 0.45 & $0.7 \pm 0.5$ & $0.96 \pm 0.25$ & $1.08 \pm 0.04$ \\
\hline $1 c^{d}$ & $\mathrm{NH}$ & $\mathrm{H}$ & $\mathrm{Cl}$ & $\mathrm{H}$ & $<20$ & $>50$ & 7.3 & $15.6 \pm 2.2$ & $>20$ & $11.5 \pm 1.5$ \\
\hline $1 d^{e}$ & $\mathrm{NH}$ & $\mathrm{OCH}_{3}$ & $\mathrm{H}$ & $\mathrm{H}$ & 75 & 0.97 & 0.80 & $6.03 \pm 1.81$ & $9.43 \pm 0.21$ & $0.80 \pm 0.14$ \\
\hline $1 \mathrm{e}^{e}$ & $\mathrm{NH}$ & $\mathrm{Cl}$ & $\mathrm{H}$ & $\mathrm{H}$ & $<20$ & n.d. & 7.13 & $>20$ & $10.4 \pm 1.8$ & $6.10 \pm 1.44$ \\
\hline $1 f^{e}$ & $\mathrm{NH}$ & $\mathrm{Br}$ & $\mathrm{H}$ & $\mathrm{H}$ & $<20$ & n.d. & 7.00 & $>20$ & $10.6 \pm 1.6$ & $7.67 \pm 1.26$ \\
\hline $1 g^{e}$ & $\mathrm{NH}$ & $\mathrm{F}$ & $\mathrm{H}$ & $\mathrm{H}$ & 52 & n.d. & 4.51 & $14.0 \pm 2.1$ & $9.76 \pm 0.68$ & $2.06 \pm 1.04$ \\
\hline $1 h^{e}$ & $\mathrm{NH}$ & $\mathrm{CF}_{3}$ & $\mathrm{H}$ & $\mathrm{H}$ & $<20$ & n.d. & 5.02 & $>20$ & $13.5 \pm 2.1$ & $11.8 \pm 2.5$ \\
\hline $1 \mathrm{i}^{e}$ & $\mathrm{NH}$ & $\mathrm{OCH}_{3}$ & $\mathrm{OCH}_{3}$ & $\mathrm{H}$ & 97 & 0.11 & 1.50 & $1.50 \pm 0.29$ & $2.32 \pm 0.41$ & $1.63 \pm 0.35$ \\
\hline $1 j^{e}$ & $\mathrm{NH}$ & $\mathrm{OCH}_{3}$ & $\mathrm{OCH}_{3}$ & $\mathrm{OCH}_{3}$ & 81 & 0.27 & 1.99 & $1.26 \pm 0.17$ & $1.92 \pm 0.31$ & $1.08 \pm 0.19$ \\
\hline $2 a$ & & $\mathrm{H}$ & $\mathrm{H}$ & $\mathrm{H}$ & 10 & n.d. & 17.1 & $>20$ & $>20$ & $>20$ \\
\hline $2 b$ & & $\mathrm{H}$ & $\mathrm{OCH}_{3}$ & $\mathrm{H}$ & 20 & n.d. & $>20$ & $>20$ & $>20$ & $>20$ \\
\hline $2 c$ & & $\mathrm{H}$ & $\mathrm{Cl}$ & $\mathrm{H}$ & 12 & n.d. & 10.2 & $16.0 \pm 1.7$ & $5.83 \pm 0.84$ & $11.6 \pm 3.3$ \\
\hline $3 a$ & $\mathrm{NH}$ & $\mathrm{H}$ & $\mathrm{H}$ & $\mathrm{H}$ & 88 & 0.56 & 0.53 & $1.25 \pm 0.18$ & $0.95 \pm 0.22$ & $0.93 \pm 0.29$ \\
\hline $3 b$ & $\mathrm{NH}$ & $\mathrm{H}$ & $\mathrm{OCH}_{3}$ & $\mathrm{H}$ & 91 & 0.52 & 0.11 & $0.084 \pm 0.022$ & $0.12 \pm 0.02$ & $0.13 \pm 0.02$ \\
\hline $3 c$ & $\mathrm{NH}$ & $\mathrm{H}$ & $\mathrm{Cl}$ & $\mathrm{H}$ & 62 & n.d. & 2.55 & $2.33 \pm 0.40$ & $2.29 \pm 0.85$ & $2.52 \pm 0.22$ \\
\hline $3 d$ & $\mathrm{NH}$ & $\mathrm{OCH}_{3}$ & $\mathrm{H}$ & $\mathrm{H}$ & 95.4 & 0.18 & 0.39 & $0.78 \pm 0.44$ & $1.57 \pm 0.25$ & $1.08 \pm 0.45$ \\
\hline $3 e$ & $\mathrm{NH}$ & $\mathrm{Cl}$ & $\mathrm{H}$ & $\mathrm{H}$ & 21 & n.d. & 4.39 & $8.30 \pm 0.26$ & $9.40 \pm 2.35$ & $6.67 \pm 2.35$ \\
\hline $3 f$ & $\mathrm{NH}$ & $\mathrm{Br}$ & $\mathrm{H}$ & $\mathrm{H}$ & 53 & n.d. & 3.11 & $5.10 \pm 1.84$ & $9.06 \pm 2.21$ & $4.03 \pm 1.04$ \\
\hline $3 g$ & $\mathrm{NH}$ & $\mathrm{F}$ & $\mathrm{H}$ & $\mathrm{H}$ & 99.7 & 0.092 & 0.28 & $1.10 \pm 0.27$ & $1.23 \pm 0.45$ & $0.73 \pm 0.15$ \\
\hline $3 \mathrm{~h}$ & $\mathrm{NH}$ & $\mathrm{CF}_{3}$ & $\mathrm{H}$ & $\mathrm{H}$ & 17 & n.d. & 4.95 & $0.83 \pm 0.07$ & $3.98 \pm 0.60$ & $1.13 \pm 0.17$ \\
\hline $3 \mathbf{i}$ & $\mathrm{NH}$ & $\mathrm{OCH}_{3}$ & $\mathrm{OCH}_{3}$ & $\mathrm{H}$ & 94.8 & 0.19 & 1.93 & $0.54 \pm 0.08$ & $0.67 \pm 0.08$ & $0.66 \pm 0.12$ \\
\hline $3 \mathbf{j}$ & $\mathrm{NH}$ & $\mathrm{OCH}_{3}$ & $\mathrm{OCH}_{3}$ & $\mathrm{OCH}_{3}$ & 93.8 & 0.016 & 1.30 & $1.85 \pm 0.71$ & $0.75 \pm 0.05$ & $1.30 \pm 0.26$ \\
\hline $3 \mathbf{k}$ & $\mathrm{NCH}_{3}$ & $\mathrm{H}$ & $\mathrm{H}$ & $\mathrm{H}$ & 2 & n.d. & 16.0 & $>20$ & $13.0 \pm 0.7$ & $18.1 \pm 1.1$ \\
\hline $4 a$ & $\mathrm{NHCH}_{2}$ & $\mathrm{H}$ & $\mathrm{H}$ & $\mathrm{H}$ & 10 & n.d. & 14.8 & $9.65 \pm 1.71$ & $11.4 \pm 1.1$ & $13.8 \pm 1.8$ \\
\hline $4 b$ & $\mathrm{NHCH}_{2}$ & $\mathrm{H}$ & $\mathrm{OCH}_{3}$ & $\mathrm{H}$ & 38 & n.d. & 16.3 & $2.71 \pm 0.22$ & $9.34 \pm 0.71$ & $8.63 \pm 0.21$ \\
\hline $4 c$ & $\mathrm{NHCH}_{2}$ & $\mathrm{H}$ & $\mathrm{Cl}$ & $\mathrm{H}$ & 11 & n.d. & 14.3 & $5.42 \pm 0.72$ & $8.38 \pm 0.81$ & $7.87 \pm 0.32$ \\
\hline $4 d$ & $\mathrm{NHCH}_{2}$ & $\mathrm{OCH}_{3}$ & $\mathrm{H}$ & $\mathrm{H}$ & 17.7 & n.d. & 1.46 & $0.45 \pm 0.05$ & $3.63 \pm 0.35$ & $9.50 \pm 3.54$ \\
\hline $4 e$ & $\mathrm{NHCH}_{2}$ & $\mathrm{Cl}$ & $\mathrm{H}$ & $\mathrm{H}$ & 5.0 & n.d. & 5.55 & $0.45 \pm 0.15$ & $4.76 \pm 0.86$ & $8.60 \pm 2.74$ \\
\hline $4 f$ & $\mathrm{NHCH}_{2}$ & $\mathrm{Br}$ & $\mathrm{H}$ & $\mathrm{H}$ & 5.1 & n.d. & 0.35 & $0.47 \pm 0.13$ & $3.40 \pm 0.75$ & $0.78 \pm 0.25$ \\
\hline $4 g$ & $\mathrm{NHCH}_{2}$ & $\mathrm{OCH}_{3}$ & $\mathrm{OCH}_{3}$ & $\mathrm{H}$ & 16.7 & n.d. & $>20$ & $9.83 \pm 2.27$ & $8.93 \pm 1.27$ & $5.73 \pm 1.74$ \\
\hline $4 \mathrm{~h}$ & $\mathrm{NHCH}_{2}$ & $\mathrm{OCH}_{3}$ & $\mathrm{OCH}_{3}$ & $\mathrm{OCH}_{3}$ & 11.2 & n.d. & 7.92 & $1.57 \pm 0.23$ & $2.73 \pm 0.43$ & $5.4 \pm 1.25$ \\
\hline Semaxanib & & & & & 40 & 12.9 & 13.6 & $38 \pm 1$ & $37 \pm 3$ & $27 \pm 2$ \\
\hline
\end{tabular}

${ }^{a}$ Percentage of kinase inhibition obtained at $7 \mu \mathrm{M}$ of the test compound. ${ }^{b} \mathrm{IC}_{50}$ values represent the concentration that induces the $50 \%$ reduction in enzyme activity. ${ }^{c} \mathrm{GI}_{50}$ values represent the concentration $(\mu \mathrm{M})$ of compound able to produce $50 \%$ cell death with respect to the control culture. ${ }^{d}$ Data from ref $18 .{ }^{e}$ Data from ref 19.

activity of $\mathbf{2 - 4}$, along with that of representative compounds from series $1(\mathbf{1} \mathbf{a}-\mathbf{j})$ expressed as inhibition percentage at $7 \mu \mathrm{M}$ concentration and as $\mathrm{IC}_{50}$ values for the most active compounds. Good to high values of KDR percentage of inhibition were recorded for the 2 -anilino substituted derivatives $(\mathbf{3} \mathbf{a}-\mathbf{j})$, and in most cases, these are higher than that exerted by the reference semaxanib. Both the deletion of the amino group $(2 \mathbf{a}-\mathbf{c})$ or the addition of a methylene spacer $(\mathbf{4} \mathbf{a}-\mathbf{h})$ reduced the inhibitory efficacy against the target protein. Also, the insertion of a methyl on the amino group of $\mathbf{3 a}$, yielding $\mathbf{3 k}$, determines a loss of inhibitory activity.

These SARs resemble the general trend shown by the benzothiopyrano derivatives of series $\mathbf{1}^{18,19}$ and confirmed the crucial role of the 2-anilino side moiety in the interaction with the enzyme.

Also, a similar effect of the substitution pattern of the pendant phenyl ring on the KDR inhibitory activity was observed within the two subseries $(\mathbf{1} \mathbf{a}-\mathbf{j}$ and $\mathbf{3 a}-\mathbf{j}):(i)$ compounds featuring one or more methoxy groups showed the highest inhibition percentages; ( $i$ ) the replacement of the $\mathrm{R}_{4}$ - or $\mathrm{R}_{3}$-methoxy with electron-withdrawing $\mathrm{Cl}, \mathrm{Br}$, or $\mathrm{CF}_{3}$ groups drastically decreases the activity, with the $\mathrm{R}_{3}$-fluorine-substituted ligand $3 \mathrm{~g}$ that represent an exception to this trend. Taken together, all these findings suggest the 2 -anilinopyridothiopiranopyrimidines would interact with KDR with basically the same pattern described for their deaza benzothiopyrano analogs. Of note, the 
presence of an additional nitrogen atom produced a gain in the inhibitory potency of the new compounds, as evidenced by the pairwise comparison between KDR inhibition percentage values of $\mathbf{1 a}-\mathbf{j}$ and $\mathbf{3 a}-\mathbf{j}$. Specifically, the most active pyridothiopyrano derivatives (3a, 3b, 3d, 3g, 3i , 3j) show KDR inhibition percentage ranging from 88 to $99.7 \%$.

The $\mathrm{IC}_{50}$ values (Table 1) assessed for the most active compounds (3a, $\mathbf{3 b}, \mathbf{3 d}, \mathbf{3 g}, \mathbf{3} \mathbf{i}$, and $\mathbf{3} \mathbf{j}$ ) confirmed a very high capacity of inhibiting the enzyme, with values ranging from 0.016 to $0.56 \mu \mathrm{M}$, significantly lower with respect to semaxanib $\left(\mathrm{IC}_{50} 12.9 \mu \mathrm{M}\right)$. The obtained data seemed to support the beneficial effect produced by the methoxy group on the inhibitory activity: compounds featuring one or more methoxy groups are very potent and show a high increase in $\mathrm{KDR}$ inhibitory activity with respect to their deaza analogues $\left(3 \mathbf{b} \mathrm{IC}_{50}\right.$ $0.52 \mu \mathrm{M}$ vs $1 \mathrm{~b} \mathrm{IC} \mathrm{IC}_{50} 2.7 \mu \mathrm{M}, 3 \mathrm{~d} \mathrm{IC}_{50} 0.18 \mu \mathrm{M}$ vs $1 \mathrm{~d} \mathrm{IC}{ }_{50} 0.97 \mu \mathrm{M}$, 3 j IC I0 $_{50} 0.016 \mu \mathrm{M}$ vs $\left.1 j \mathrm{IC}_{50} 0.27 \mu \mathrm{M}\right)$; the only exception is represented by $3 \mathbf{i}$ and $1 \mathbf{i}\left(\mathrm{IC}_{50} 0.19 \mu \mathrm{M}\right.$ and $0.11 \mu \mathrm{M}$, respectively).

To rationalize the activity featured by the novel pyridothiopyranopyrimidines, in silico studies were undertaken on compound $3 \mathbf{j}$, the one with the lowest $\mathrm{IC}_{50}$ on $\mathrm{KDR}$. To this end, $3 \mathbf{j}$ was virtually docked with AutoDock Vina ${ }^{24}$ on the VEGFR2 DFG-out conformation crystal structure with PDB code $3 \mathrm{EWH},{ }^{25}$ a protocol which already yielded successful results. ${ }^{19}$ The lowest energy binding conformation of the docked ligand $\left(\Delta G_{\mathrm{VINA}}=-8.2 \mathrm{kcal} / \mathrm{mol}\right)$ proved to be consistent with the results of our previous studies on similar scaffolds. ${ }^{19}$ The tricyclic core is lodged in the lipophilic gorge formed by the residues L840, V848, A866, V899, and L1035, establishing van der Waals interactions with them (Figure 1a).

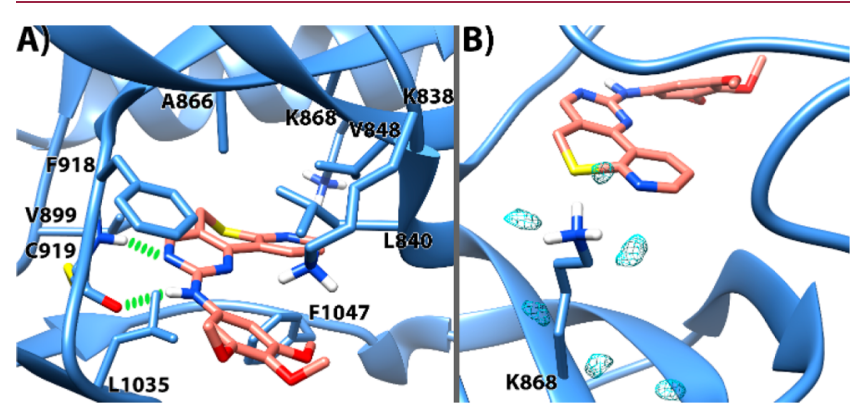

Figure 1. (a) Binding mode of $\mathbf{3} \mathbf{j}$, within the VEGFR-2 active site. $\mathbf{3} \mathbf{j}$ is represented as pink sticks while the protein as blue sticks and ribbons. H-bonds are depicted as dashed green lines. (b) $0.9 \mathrm{kcal} / \mathrm{mol} / \AA^{3}$ isosurface (represented as cyan meshes) of the solute-water interactions in the VEGFR2 binding site. The pictures were both rendered with the UCSF Chimera software. ${ }^{30}$

One of the pyrimidine nitrogen atoms and the exocyclic $\mathrm{NH}$ of $3 \mathbf{j}$ engage a key double $\mathrm{H}$-bonding interaction with the backbone $\mathrm{NH}$ and $\mathrm{CO}$ of the hinge region C919, accounting for the potency loss in the derivatives not featuring the $\mathrm{NH}$ spacer. Also, the ligand is sandwiched between F918 and F1047 establishing charge-transfer interactions, while the pendant anilino aryl moiety, pointing outside of the active site, is favorably positioned to allow for a cation $-\pi$ interaction with the positively charged side-chain of K838. As happened for the parent compounds belonging to series 1 , we infer that electrondonating substituents on the pendant aniline ring, such as the methoxy groups featured by $\mathbf{3} \mathbf{b}, \mathbf{3} \mathbf{d}, \mathbf{3} \mathbf{i}$, and $\mathbf{3} \mathbf{j}$, increase the negative electrostatic potential, allowing for a stronger charge transfer interaction, ${ }^{26}$ which in turn should result in a more effective enzyme inhibition. Along this line, electron-withdrawing substituents in the meta position of the same pendant aniline ring are detrimental for the inhibitory activity (see compounds $\mathbf{3 e}, \mathbf{3 f}$, and $\mathbf{3 h}$ in Table 1 ). Additionally, in the present work, we also attempted to probe the water-mediated contacts of the ligand within the binding site. To this end, the Grid Inhomogeneous Solvation Theory Method (GIST) tool, ${ }^{27,28}$ part of the Amber14 molecular dynamics package, ${ }^{29}$ was employed. GIST estimates thermodynamic values for the water molecules occupying the binding pocket; therefore, here this method was employed to compute a map of the interactions of the water molecules with both the protein and the ligand. Through Amber14, a minimization and equilibration protocol was performed on the enzyme/ligand complex (see SI). Then, the system underwent $50 \mathrm{~ns}$ of $\mathrm{MD}$ simulation with the solute restrained and the solvent molecules free to move. The resulting trajectory of the water molecules in a grid centered around the ligand was analyzed through GIST. According to this in silico study (Figure 1b), a water molecule positioned between K868 and the nitrogen atom of the pyridine moiety of the tricyclic scaffold was found to be highly energetically favorable, thereby indicating the possible occurrence of a water-mediated H-bond. This might explain the increased potency compared to the parent compounds which, being devoid of the pyridine nitrogen, could not establish this additional H-bonding contact.

The new pyridothiopyranopyrimidines $2-4$ were then evaluated for their effect on cell growth of human umbilical vein endothelial cells (HUVEC), using semaxanib ${ }^{23}$ as a reference (Table 1). The majority of the new compounds exert a detectable antiproliferative effect on HUVEC cells, with $\mathrm{GI}_{50}$ values ranging in the low micromolar/submicromolar range (from 0.11 to $17.1 \mu \mathrm{M}$ ). The 2 -anilino-substituted subseries $(3 \mathbf{a}-\mathbf{k})$ emerged as the most interesting, as the majority of the compounds are able to exert a significant antiproliferative effect with $\mathrm{GI}_{50}$ values several fold lower than the corresponding value recorded for semaxanib (with the only exception of $3 \mathbf{k}$ ) and in some cases even submicromolar $\left(3 \mathbf{a ~ G I}{ }_{50} 0.53 \mu \mathrm{M}, 3 \mathbf{b} \mathrm{GI}_{50} 0.11\right.$ $\left.\mu \mathrm{M}, 3 \mathrm{~d} \mathrm{GI}_{50} 0.39 \mu \mathrm{M}, 3 \mathrm{~g} \mathrm{GI} \mathrm{I}_{50} 0.28 \mu \mathrm{M}\right)$. The nature of the substituents on the pendant phenyl group slightly modulates the antiproliferative effects, with no-substitution (3a) or insertion of one or more methoxy electron donating groups $(3 \mathbf{b}, 3 \mathbf{d}, 3 \mathbf{i}$, and $3 \mathbf{j})$ that produce highly cytotoxic compounds as well as the presence of a fluorine atom at $\mathrm{R}_{3}(3 \mathrm{~g})$. The low potency of $3 \mathrm{k}$ confirms the crucial role played by the hydrogen bound to the amino group, in agreement with the lack of any significant inhibitory effect on KDR. Accordingly, also the 2-phenyl substituted derivatives $\mathbf{2 a}-\mathbf{c}$ exhibited low or null cytotoxic capacities in HUVEC. Compounds from the 2-benzylaminosubstituted subseries $(\mathbf{4 a}-\mathbf{h})$ generally displayed comparable and low cytotoxic potencies, with the exception of the $R_{3}$ methoxy $(\mathbf{4 d})$ and $\mathrm{R}_{3}$-bromine (4f) derivatives $\left(\mathrm{GI}_{50}\right.$ values 1.46 and $0.35 \mu \mathrm{M}$, respectively). The significant antiproliferative effect exerted by $\mathbf{4} \mathbf{d}$ and $\mathbf{4} \mathbf{f}$ is in contrast with the low inhibitory activity on KDR and suggests the involvement of cell target(s) different with respect to the VEGFR-2 kinase pathway.

The antiproliferative activity of derivatives $2-\mathbf{4}$ against a panel of human tumor cell lines (HeLa, A-431, and MSTO$211 \mathrm{H})$ was also evaluated to define their cell proliferation profile. The results, in Table 1 (semaxanib was taken as reference), once again highlighted a crucial role for the length of the 2 -side chain and the presence of the $\mathrm{NH}$ group, as significant cytotoxic effects were observed for the majority of 2-anilino 
substituted derivatives $\mathbf{3 a}-\mathbf{j}\left(\mathrm{GI}_{50}\right.$ values in the low micromolar/ submicromolar range), with a general enhancement of activity with respect to compounds $\mathbf{1 a}-\mathbf{j} \cdot{ }^{18,19}$ In addition, a notable effect might also be ascribable to the methoxy or poly methoxy substitution of the pendant phenyl ring, being $\mathbf{3 b}, \mathbf{3} \mathbf{d}, \mathbf{3} \mathbf{i}$, and $\mathbf{3} \mathbf{j}$ among the most effective derivatives. Within the 2-phenyl- (2ac) and 2-benzyl- $(\mathbf{4 a}-\mathbf{h})$ subseries, only compounds $\mathbf{4 d}, \mathbf{4 e}$, and 4f show an evident antiproliferative effect, which appears more significant in HeLa (4d, 4e, and 4f) and MSTO-211H (4f). Interestingly, these compounds showed low percentages of KDR inhibition (Table 1), supporting the hypothesis that their activity is probably mediated by interactions with other molecular targets and/or kinases.

In these veins, we also attempted to profile the selectivity of the best performing 2 -anilino-substituted $\mathbf{3} \mathbf{b}, \mathbf{3} \mathbf{i}$, and $3 \mathbf{j}$ compounds. For this purpose, the effects of $\mathbf{3} \mathbf{b}, \mathbf{3} \mathbf{i}$, and $3 \mathbf{j}$ were assessed against a set of six human (h) kinases, i.e. AurA/ Aur2 kinase, CDC2/CDK1, EGFR kinase, PDGFR- $\beta$ kinase, RAF-1 kinase, and Src kinase, which are reported to be mainly involved in cell proliferation. The obtained results suggest $\mathbf{3 b}, \mathbf{3} \mathbf{i}$, and $3 \mathbf{j}$ as multitarget inhibitors (Figure 2, Tables S1a and S1b).

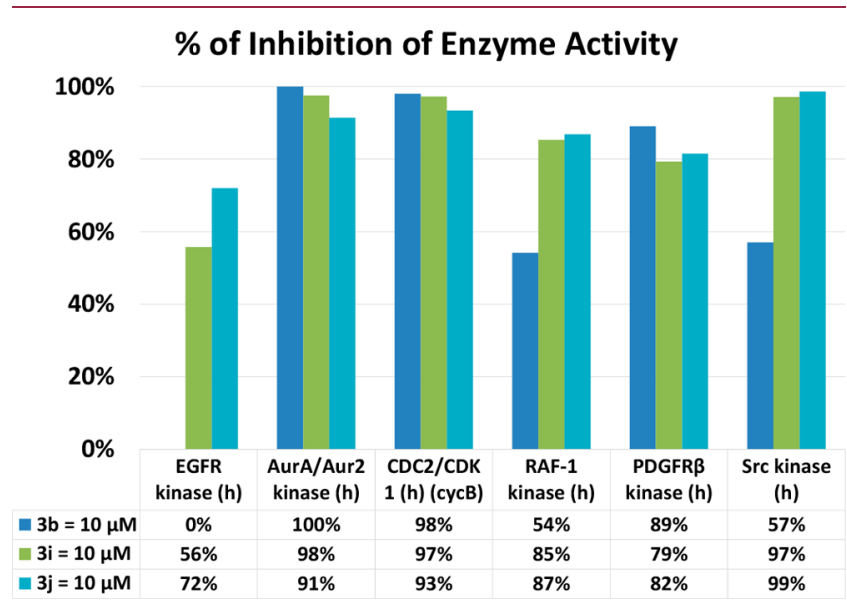

Figure 2. Percentage of inhibition of kinase activity in the presence of compounds $3 \mathbf{b}, 3 \mathbf{i}$, and $3 \mathbf{j}$ at $10 \mu \mathrm{M}$.

Specifically, $3 \mathbf{b}$ ( $\mathrm{R}_{4}$-methoxy substituted) produces a relevant inhibitory effect also against Aurora (AurA/Aur2) kinase, a nuclear serine/threonine protein kinase involved in many functions related to mitosis, cyclin-dependent protein kinase (CDC2/CDK1 cycB), and beta-type platelet-derived growth factor receptor (PDGFR beta kinase) (Figure 2, Tables S1a and $\mathrm{S} 1 \mathrm{~b})$. In addition, good inhibition properties toward the nonreceptor tyrosine kinase Src and RAF proto-oncogene serine/threonine-protein kinase (RAF-1) were also observed. Interestingly, $3 \mathbf{i}$ and $3 \mathbf{j}$, featuring a $\mathrm{R}_{3}, \mathrm{R}_{4}$-dimethoxy and $R_{3}, R_{4}, R_{5}$-trimethoxy substitution, respectively, show a further lowering in the selectivity profile with respect to $3 \mathbf{b}$ (EGFR I\% = 0 at $10 \mu \mathrm{M}$ ), due to the occurrence of inhibitory properties toward epidermal growth factor receptor (EGFR) and an increase in the percentage of inhibition of Src and RAF-1 kinases.

In conclusion, in the present work, we have developed a new set of pyridothiopyranopyrimidine derivatives (2-4), designed as azaisosters of the benzothiopyranopyrimidines previously described by us. The 2 -anilino substituted derivatives (series 3 ) showed good to high potency in KDR inhibition (submicromolar/nanomolar $\mathrm{IC}_{50}$ values ranging from 0.016 to $0.56 \mu \mathrm{M}$ ).
Of note, the presence of an additional nitrogen atom produced a gain in the potency of the newly developed compounds, as evidenced by the pairwise comparison between KDR inhibition data of series 1 and 3. Detailed in silico experiments allowed clarifying at molecular level the interaction pattern established by the new compounds with the KDR domain of VEGFR-2. Furthermore, the majority of these compounds exerted a detectable antiproliferative effect on HUVEC cells, thus confirming the ability to affect KDR activity, as well as on a panel of three human tumor cell lines (HeLa, A-431, and MSTO-211H), with GI $_{50}$ values ranging in the low micromolar/ submicromolar range. Overall, these newly described derivatives, and in particular compounds $3 \mathbf{a}-\mathbf{j}$, displayed an enhanced antiproliferative effect with respect to compounds $\mathbf{1 a - j}$, previously described by us. ${ }^{18,19}$ Finally, investigation on the selectivity profile of representative 2-anilino-substituted compounds $3 \mathbf{b}, \mathbf{3} \mathbf{i}$, and $3 \mathbf{j}$ revealed a multiplicity of kinase targets that could account for the significant antiproliferative effect produced by these pyridothiopyranopyrimidine derivatives on tumor cells. These results provide a solid basis for further development of these new MTKIs as antiangiogenic and antiproliferative agents in the treatment of solid tumors with high resistance and metastatic potential.

\section{ASSOCIATED CONTENT}

\section{Supporting Information}

The Supporting Information is available free of charge on the ACS Publications website at DOI: 10.1021/acsmedchemlett.8b00499.

Experimental procedures for the synthesis of all new compounds; procedures for biological evaluation, molecular modeling methods, additional tables, and ${ }^{1} \mathrm{H}$ and ${ }^{13} \mathrm{C}$ NMR spectra (PDF)

\section{AUTHOR INFORMATION}

\section{Corresponding Authors}

*(ST) Phone: +39 05033 19 547. E-mail: sabrina.taliani@unipi. it.

*(SC) Phone: +39 08232747 89. E-mail: sandro.cosconati@ unicampania.it.

ORCID $\odot$

Sabrina Taliani: 0000-0001-8675-939X

Giorgio Amendola: 0000-0003-4271-5031

Sandro Cosconati: 0000-0002-8900-0968

Ettore Novellino: 0000-0002-2181-2142

\section{Author Contributions}

The manuscript was written through contributions of all authors.

\section{Funding}

This work was supported by the University of Pisa (PRA Project, PRA_2018_20), University of Campania Luigi Vanvitelli (VALERE and VALERE PLUS Projects), and MIUR-PRIN 2015 (Grant 2015FCHJ8E_003).

\section{Notes}

The authors declare no competing financial interest.

\section{ABBREVIATIONS}

A-431, epidermoid carcinoma cell line; DMEDA, $N, N^{\prime}$ dimethylethylendiamine; $\mathrm{HeLa}$, cervix adenocarcinoma cell line; (h), human; HUVEC, human umbilical vein endothelial cell; KDR, human kinase insert domain receptor; MSTO-211H, 
biphasic mesothelioma cell line; MTKI, multitargeted kinase inhibitor; SAR, structure-activity relationship; TKI, tyrosine kinase inhibitor; TKR, tyrosine kinase receptor; VEGF, vascular endothelial growth factor; VEGFR, vascular endothelial growth factor receptor.

\section{REFERENCES}

(1) Gossage, L.; Eisen, T. Targeting Multiple Kinase Pathways: A Change In Paradigm. Clin. Cancer Res. 2010, 16, 1973-1978.

(2) Knapp, S.; Sundström, M. Recently Targeted Kinases and Their Inhibitors-the Path to Clinical Trials. Curr. Opin. Pharmacol. 2014, $17,58-63$.

(3) Ma, X.; Lv, X.; Zhang, J. Exploiting Polypharmacology for Improving Therapeutic Outcome of Kinase Inhibitors (KIs): An Update of Recent Medicinal Chemistry Efforts. Eur. J. Med. Chem. 2018, 143, 449-463.

(4) Wilhelm, S. M.; Adnane, L.; Newell, P.; Villanueva, A.; Llovet, J. M.; Lynch, M. Preclinical Overview of Sorafenib, a Multikinase Inhibitor That Targets Both Raf and VEGF and PDGF Receptor Tyrosine Kinase Signaling. Mol. Cancer Ther. 2008, 7, 3129-3140.

(5) Poprach, A.; Bortlicek, Z.; Melichar, B.; Lakomy, R.; Svoboda, M.; Kiss, I.; Zemanova, M.; Fiala, O.; Kubackova, K.; Coufal, O.; Pavlik, T.; Dusek, L.; Vyzula, R.; Buchler, T. Efficacy of Sunitinib in Patients with Metastatic or Unresectable Renal Cell Carcinoma and Renal Insufficiency. Eur. J. Cancer 2015, 51, 507-513.

(6) Xu, Z.-Q.; Zhang, Y.; Li, N.; Liu, P.-J.; Gao, L.; Gao, X.; Tie, X.-J. Efficacy and Safety of Lapatinib and Trastuzumab for HER2-Positive Breast Cancer: a Systematic Review and Meta-Analysis of Randomised Controlled Trials. BMJ. Open 2017, 7, e013053.

(7) Jung, K. S.; Lee, S. J.; Park, S. H.; Lee, J.-L.; Lee, S.-H.; Lim, J. Y.; Kang, J. H.; Lee, S.; Rha, S. Y.; Lee, K. H.; Kim, H. Y.; Lim, H. Y. Pazopanib for the Treatment of Non-Clear Cell Renal Cell Carcinoma: A Single-Arm, Open-Label, Multicenter, Phase II Study. Cancer Res. Treat. 2018, 50, 488-494.

(8) Zhou, Y.; Zhang, Y.; Zou, H.; Cai, N.; Chen, X.; Xu, L.; Kong, X.; Liu, P. The Multi-Targeted Tyrosine Kinase Inhibitor Vandetanib Plays a Bifunctional Role in Non-Small Cell Lung Cancer Cells. Sci. Rep. 2015, 5, 8629.

(9) Goel, G. Evolution of Regorafenib from Bench to Bedside in Colorectal Cancer: Is It an Attractive Option or Merely a "Me Too" Drug? Cancer Manag. Res. 2018, 10, 425-437.

(10) Carmeliet, P. Angiogenesis in Life, Disease and Medicine. Nature 2005, 438, 932-936.

(11) Kerbel, R. S. Tumor angiogenesis. N. Engl. J. Med. 2008, 358, 2039-2049.

(12) Fox, S. B.; Gasparini, G.; Harris, A. L. Angiogenesis: Pathological, Prognostic, and Growth-Factor Pathways and Their Link to Trial Design and Anticancer Drugs. Lancet Oncol. 2001, 2, 278-289.

(13) Simons, M.; Gordon, E.; Claesson-Welsh, L. Mechanisms and regulation of endothelial VEGF receptor signalling. Nat. Rev. Mol. Cell Biol. 2016, 17, 611-625.

(14) Dalla Via, L.; Gia, O.; Marciani Magno, S.; Da Settimo, A.; Marini, A. M.; Primofiore, G.; Da Settimo, F.; Salerno, S. Synthesis, in Vitro Antiproliferative Activity and DNA-Interaction of Benzimidazoquinazoline Derivatives as Potential Anti-Tumor Agents. Farmaco 2001, 56 (3), 159-167.

(15) Dalla Via, L.; Gia, O.; Marciani Magno, S.; Da Settimo, A.; Primofiore, G.; Da Settimo, F.; Simorini, F.; Marini, A. M. Dialkylaminoalkylindolonaphthyridines as Potential Antitumour Agents: Synthesis, Cytotoxicity and DNA Binding Properties. Eur. J. Med. Chem. 2002, 37, 475-486.

(16) Dalla Via, L.; Marciani Magno, S.; Gia, O.; Marini, A. M.; Da Settimo, F.; Salerno, S.; La Motta, C.; Simorini, F.; Taliani, S.; Lavecchia, A.; Di Giovanni, C.; Brancato, G.; Barone, V.; Novellino, E. Benzothiopyranoindole-Based Antiproliferative Agents: Synthesis, Cytotoxicity, Nucleic Acids Interaction, and Topoisomerases Inhibition Properties. J. Med. Chem. 2009, 52, 5429-5441.
(17) Taliani, S.; Pugliesi, I.; Barresi, E.; Salerno, S.; Marchand, C.; Agama, K.; Simorini, F.; La Motta, C.; Marini, A. M.; Leva, F. S. D.; Marinelli, L.; Cosconati, S.; Novellino, E.; Pommier, Y.; Di Santo, R.; Da Settimo, F. Phenylpyrazolo[1,5-a] Quinazolin-5(4H)-One: A Suitable Scaffold for the Development of Noncamptothecin Topoisomerase I (Top1) Inhibitors. J. Med. Chem. 2013, 56, 7458-7462.

(18) Salerno, S.; Marini, A. M.; Fornaciari, G.; Simorini, F.; La Motta, C.; Taliani, S.; Sartini, S.; Da Settimo, F.; García-Argáez, A. N.; Gia, O.; Cosconati, S.; Novellino, E.; Docon, P.; Fioravanti, A.; Orlandi, P.; Bocci, G.; Dalla Via, L. Investigation of New 2-Aryl Substituted Benzothiopyrano[4,3-d]Pyrimidines as Kinase Inhibitors Targeting Vascular Endothelial Growth Factor Receptor 2. Eur. J. Med. Chem. 2015, 103, 29-43.

(19) Salerno, S.; García-Argáez, A. N.; Barresi, E.; Taliani, S.; Simorini, F.; La Motta, C.; Amendola, G.; Tomassi, S.; Cosconati, S.; Novellino, E.; Da Settimo, F.; Marini, A. M.; Dalla Via, L. New Insights in the Structure-Activity Relationships of 2-Phenylamino-Substituted Benzothiopyrano[4,3-d]Pyrimidines as Kinase Inhibitors. Eur. J. Med. Chem. 2018, 150, 446-456.

(20) Primofiore, G.; Marini, A. M.; Da Settimo, F.; Salerno, S.; Bertini, D.; Dalla Via, L.; Marciani Magno, S. Synthesis of novel 1,4dihydropyrido $\left[3^{\prime}, 2^{\prime}: 5,6\right]$ thiopyrano $[4,3-c]$ pyrazoles and $5 \mathrm{H}$-pyrido$\left[3^{\prime}, 2^{\prime}: 5,6\right]$ thiopyrano $[4,3-\mathrm{d}]$ pyrimidines as potential antiproliferative agents. J. Heterocycl. Chem. 2003, 40, 783-788.

(21) Coxon, G. D.; Furman, B. L.; Harvey, A. L.; Mctavish, J.; Mooney, M. H.; Arastoo, M.; Kennedy, A. R.; Tettey, J. M.; Waigh, R. D. Benzylguanidines and Other Galegine Analogues Inducing Weight Loss in Mice. J. Med. Chem. 2009, 52, 3457-3463.

(22) Dalla Via, L.; Marini, A. M.; Salerno, S.; Toninello, A. Mitochondrial Permeability Transition Induced by Novel Pyridothiopyranopyrimidine Derivatives: Potential New Antimitochondrial Antitumour Agents. Biochem. Pharmacol. 2006, 72, 1657-1667.

(23) Morabito, A.; De Maio, E.; Di Maio, M.; Normanno, N.; Perrone, F. Tyrosine Kinase Inhibitors of Vascular Endothelial Growth Factor Receptors in Clinical Trials: Current Status and Future Directions. Oncologist 2006, 11, 753-764.

(24) Trott, O.; Olson, A. J. AutoDock Vina: Improving the Speed and Accuracy of Docking with a New Scoring Function, Efficient Optimization, and Multithreading. J. Comput. Chem. 2009, 31, 455461.

(25) Cee, V. J.; Cheng, A. C.; Romero, K.; Bellon, S.; Mohr, C.; Whittington, D. A.; Bak, A.; Bready, J.; Caenepeel, S.; Coxon, A.; Deak, H. L.; Fretland, J.; Gu, Y.; Hodous, B. L.; Huang, X.; Kim, J. L.; Lin, J.; Long, A. M.; Nguyen, H.; Olivieri, P. R.; Patel, V. F.; Wang, L.; Zhou, Y.; Hughes, P.; Geuns-Meyer, S. Pyridyl-Pyrimidine Benzimidazole Derivatives as Potent, Selective, and Orally Bioavailable Inhibitors of Tie-2 Kinase. Bioorg. Med. Chem. Lett. 2009, 19, 424-427.

(26) Mecozzi, S.; West, A. P.; Dougherty, D. A. Cation-Pi Interactions in Aromatics of Biological and Medicinal Interest: Electrostatic Potential Surfaces as a Useful Qualitative Guide. Proc. Natl. Acad. Sci. U. S. A. 1996, 93, 10566-10571.

(27) Ramsey, S.; Nguyen, C.; Salomon-Ferrer, R.; Walker, R. C.; Gilson, M. K.; Kurtzman, T. Solvation Thermodynamic Mapping of Molecular Surfaces in AmberTools: GIST. J. Comput. Chem. 2016, 37, 2029-203.

(28) Nguyen, C. N.; Young, T. K.; Gilson, M. K. Grid Inhomogeneous Solvation Theory: Hydration Structure and Thermodynamics of the Miniature Receptor Cucurbit[7]Uril. J. Chem. Phys. 2012, 137, 14990.

(29) Salomon-Ferrer, R.; Case, D. A.; Walker, R. C. An Overview of the Amber Biomolecular Simulation Package. WIREs Comput. Mol. Sci. 2013, 3, 198-210.

(30) Pettersen, E. F.; Goddard, T. D.; Huang, C. C.; Couch, G. S.; Greenblatt, D. M.; Meng, E. C.; Ferrin, T. E. UCSF Chimera-A Visualization System for Exploratory Research and Analysis. J. Comput. Chem. 2004, 25, 1605-1612. 